\title{
Cutaneous Leishmaniasis Caused by Members of Leishmania braziliensis Complex in Nayarit, State of Mexico
}

\author{
Gustavo Sanchez-Tejeda, Noris Rodríguez*, Carlos I Parra**, \\ Omar Hernandez-Montes***, Douglas C Barker****, Amalia Monroy-Ostria***/+
}

\begin{abstract}
Coordenación de Vigilancia Epidemiologica, SSA, Mexico D.F. 06700 *Instituto de Biomedicina, Universidad Central de Venezuela, Caracas, Venezuela **Secretaria de Salud, Tepic Nayarit, Mexico

****Departamento de Inmunología, ENCB, IPN, Carpio y Plan de Ayala, 11340 México, D.F. ****MRC Outstation of NIMR, Molteno Laboratories, Department of Pathology, Tennis Court Road, Cambridge, UK
\end{abstract}

\begin{abstract}
An epidemiological study was carried out in the northern Mexican state, Nayarit. Fourteen patients with possible cutaneous leishmaniasis skin lesions gave positive Montenegro skin tests. Biopsies were taken from the skin ulcer and analyzed by polymerase chain reaction (PCR) with specific primers for the Leishmania mexicana complex; however all biopsies were not amplified. PCR carried out with specific primers for the L. braziliensis complex resulted in the amplification of all patient DNA. DNA from 12 out of 14 biopsies gave positive amplification with primers species specific for $\mathrm{L}$. (Viannia) braziliensis and hybridized with a species specific L. (V.) braziliensis probe. These results demonstrate the presence in Nayarit of at least two members of the L. braziliensis complex. Most of the cutaneous lesions were caused by L. (V.) braziliensis and two by another species belonging to the L. braziliensis complex. As far as we are aware, this is the first report of L. (V.) braziliensis in Nayarit. The main risk factor associated with the contraction of this disease in Nayarit is attributed to working on coffee plantations.
\end{abstract}

Key words: mucocutaneous leishmaniasis - Leishmania (Viannia) braziliensis - epidemiology - Nayarit - Mexico

Leishmaniasis is represented by a group of clinical entities ocurring in 79 countries worldwide. The disease occurs at a rate of 400,000 cases per year with 12 million currently infected and 350 million at risk (Ashford et al. 1992). The causative agent of leishmaniasis is the protozoan parasite Leishmania.

American cutaneous leishmaniasis is characterized by a spectrum of clinical presentations. Included in the spectrum are the following: localized cutaneous leishmaniasis (LCL) caused by $L$. (L.) mexicana and by members of the L. braziliensis complex; diffuse cutaneous leishmaniasis (DCL) caused by $L$. ( $L$.) amazonensis, $L$. (L.) venezuelensis and $L$. (L.) pifanoi; and mucocutaneous leishmaniasis (MCL) caused by members of the $L$. braziliensis complex (Lainson 1983, Velasco et al. 1989a).

Leishmaniasis in Mexico is considered to be a public health problem since it has been found in at

\footnotetext{
This work was supported by grants from DEPI-IPN and CONACYT (26503-N).

${ }^{+}$Correspondig author and sponsored by EDD and COFAA-IPN, Mexico. Fax: +52-5-396.3503. E-mail: amonroyos@hotmail.com

Received 7 January 2000

Accepted 19 July 2000
}

least 22 states. Seidelin recorded LCL caused by L. (L.) mexicana in 1912 among chicle workers and hence gave it the name "Chicleros ulcer".

The L. braziliensis complex is defined in this paper as containing all species of the actual subgenus Viannia (Lainson \& Shaw 1987): L. (V.) braziliensis causing espundia, $L$. (V.) guyanensis causing Pian boi, $L$. (V.) panamensis and $L(V$.) peruviana.

Until 1994 only four cases of MCL were recorded in Mexico. These cases were confined to the states of Oaxaca, Veracruz and Tabasco and the causal agent was considered to be $L$. ( $L$.) mexicana. In the State of Campeche, LCL was found to be caused by members of L. mexicana complex and by members of the L. braziliensis complex (Velasco et al. 1989a,b, OPS/OMSSecretaria de Salud 1994, Perez-Motul et al. 1994, Hernandez-Montes et al. 1998).

Between 1987 and 1994, 326 cases of LCL have been recorded in Nayarit. These cases were attributed to infection with $L$. (L.) mexicana. Diagnosis of LCL was carried out by serology and skin testing, however Leishmania species were not identified. The presence of $L$. $(V$.) braziliensis has, until now, not been recorded in Nayarit (OPS/OMS 1994). Calera de Cofrados, district of Nayarit endemic for LCL, is near to the Pacific coast where the climate is hot with high humidity woods with deep hills surrounded by small brooks. The rainy 
season occurs at the beginning and middle of the year and the main occupation of the population is agriculture in particular coffee plantations.

\section{MATERIALS AND METHODS}

Leishmania species and culture conditions The reference strains of Leishmania were cultured in RPMI medium supplemented with $10 \%$ fetal calf serum at $28^{\circ} \mathrm{C}$. The reference strains of Leishmania were: $L$. (L.) mexicana MHOM/BZ/62/BEL21; L. (V.) braziliensis MHOM/BR/75/M2903.

Patients - Fourteen patients from the district Calera de Cofrados, 12 males and 2 females with cutaneous lesions suggestive to be LCL, were studied. Skin test was carried out in all of them, by injecting $0.1 \mathrm{ml}$ of leishmanin antigen in the forearm (Montenegro's antigen was prepared as described by Bray 1980). The reaction was read at 24 and $48 \mathrm{~h}$. Induration reactions of about $5 \mathrm{~mm}$ or more were considered positive. Skin biopsies from the lesion were taken for polimerase chain reaction (PCR).

Isolation of DNA - DNA was prepared by centrifuging $10^{9}$ parasites of a logarithmically growing culture at $1,900 \mathrm{~g}$ for $10 \mathrm{~min}$ at room temperature. The pellet was resuspended in $1 \mathrm{ml}$ of NET 100 (100 mM Tris-HCl, pH 8.0; 100 mM EDTA; $100 \mathrm{mM} \mathrm{NaCl}), 1 \%$ SDS and $4 \mu \mathrm{l}$ of $10 \mathrm{mg} / \mathrm{ml}$ proteinase $\mathrm{K}$ (Sigma) and incubated at $37^{\circ} \mathrm{C}$ overnight, followed by 2 phenol-chloroform extractions and ethanol precipitation. The DNA precipitate was dissolved in $500 \mu \mathrm{l}$ of TE (Tris-EDTA). DNA from tissue biopsy samples was prepared following the technique described by Hernandez-Montes et al. (1998). Briefly, tissue biopsy samples (1-2 mm) were incubated at $65^{\circ} \mathrm{C}$ for $2 \mathrm{~h}$ in $200 \mu \mathrm{l}$ of NET 10 (10 mM Tris-HCl, $\mathrm{pH} 8.0 ; 10 \mathrm{mM}$ EDTA, 10 $\mathrm{mM} \mathrm{NaCl}), 1 \%$ SDS and $4 \mu \mathrm{l}$ of $10 \mu \mathrm{g} / \mathrm{ml}$ proteinase K (Sigma) followed by 2 phenol-chloroform extractions and ethanol precipitation. The DNA precipitate was dissolved in $300 \mu \mathrm{l}$ of TE.

$P C R$ - Purified total DNA (100 ng) from positives controls or from patients biopsies were amplified in $50 \mathrm{mM} \mathrm{KCl}, 10 \mathrm{mM}$ Tris $\mathrm{HCl}(\mathrm{pH} 8.3)$, $1.5 \mathrm{mM} \mathrm{MgCl} 2$ and $0.01 \%$ gelatin in the presence of $0.2 \mathrm{mM}$ of each deoxyribonucleotide (Pharmacia), $100 \mathrm{pmol}$ of each primer and 2.5 units of Taq DNA polymerase (Perkin Elmer Cetus) in a final volume of $100 \mu \mathrm{l}$. Samples were overlaid with mineral oil (Sigma) and initially denatured at $96^{\circ} \mathrm{C}$ for $6 \mathrm{~min}$. Cycles consisted of annealing at 67.5 and $60.5^{\circ} \mathrm{C}$ for $1 \mathrm{~min}$ for $L$. mexicana and $L$. braziliensis complexes specific primers respectively and for species specific primers for $L$. $(V$.) braziliensis an annealing temperature of $65^{\circ} \mathrm{C}$. Extension at $72^{\circ} \mathrm{C}$ for $1 \mathrm{~min}$ and denaturation at $93^{\circ} \mathrm{C}$ for $30 \mathrm{sec}$. Programs were run for 35 cycles on a Cambio Intelligent Heating Block (Genesis Instruments, Cambridge, UK), a final extension cycle for $10 \mathrm{~min}$ was run. Products $(10 \mu \mathrm{l})$ were fractionated by electrophoresis in $1 \%$ agarose gels in TBE $(90 \mathrm{mM}$ Tris- $\mathrm{HCl} \mathrm{pH} 8.3,90 \mathrm{mM}$ boric acid and $25 \mathrm{mM}$ EDTA).

Genomic DNA PCR products hybridization conditions - PCR products derived from the amplification genomic DNA from patients biopsies with primers $3 \mathrm{~J} 1$ and $3 \mathrm{~J} 2$ specific for $L$. $(V$.) braziliensis $(10 \mu \mathrm{l})$ were electrophoresed on a $1 \%$ agarose gel in 1X TBE, southern blotted onto nylon membranes (Hybond N, Amersham) (Sambroock et al. 1989) and hybridized with probe LbJ38, which were labeled with [ $\left.{ }^{32} \mathrm{P}\right] \mathrm{d}$ ATP using the Prime it Random Primer labeling kit (Stratagene). The hybridization and the consequent washes were at medium stringency conditions as described by Rodriguez et al. (1997).

\section{RESULTS}

Skin test - All patients with suggested cutaneous lesions of LCL gave positive skin test with leishmanin, with a skin reaction of about $5 \mathrm{~mm}$ or more.

PCR - PCR of the L. mexicana complex was carried out using the M1 and M2 primers (Eresh et al. 1994). PCR resulted in specific kDNA amplification of the $L$. $(L$.) mexicana reference strain BEL21 giving an amplification band of 800-820 bp size. All DNA samples from patients biopsies were not amplified (data not shown). PCR of the L. braziliensis complex was done with the $\mathrm{B} 1$ and B2 primers (De Bruijn \& Barker 1992). These primers amplified kDNA from the $L$. (V.) braziliensis reference strain M2903 and DNA from all 14 biopsies, giving an amplification band of 750 bp (Fig. 1). In order to have a more specific identification of the Leshmania species and to know if the biopsies had $L$. (V.) braziliensis, biopsy was amplified by PCR using species specific primers. The primers used were $3 \mathrm{~J} 1$ and $3 \mathrm{~J} 2$, which amplify nuclear DNA from variants of $L$. $(V$.) braziliensis, giving an amplification band of 617 bp (Rodriguez et al. 1997). These primers amplified DNA from 12 out of 14 Mexican biopsies, giving a PCR product of $617 \mathrm{bp}$. DNA from the $L$. (L.) mexicana BEL 21 reference strain and two biopsies did not amplify with these primers (Fig. 2A).

Southern blot analysis - The LbJ38 probe, which is species specific for L. braziliensis complex (Rodriguez et al. 1997), hybridized to nuclear DNA amplified with $3 \mathrm{~J} 1$ and $3 \mathrm{~J} 2$ primers, for 11 out of 14 Mexican biopsy samples. PCR products from the $L$. (L.) mexicana BEL 21 reference strain and from samples 1, 7 and 9 did not hybridize (Fig. 2B). 


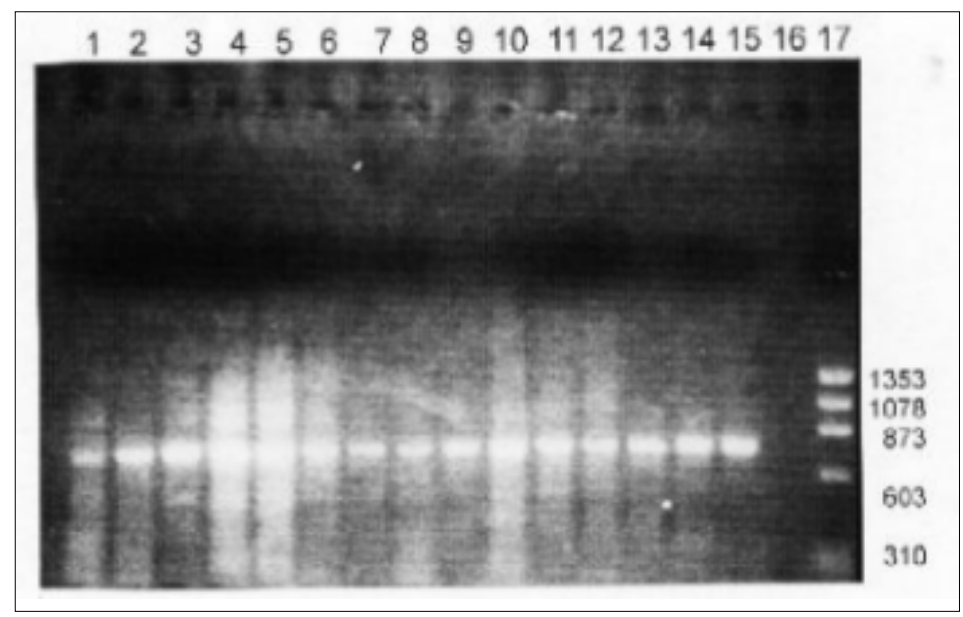

Fig. 1: specificity of polymerase chain reaction with B1 and B2 primers specific for Leishmania braziliensis complex. Photograph shows the products obtained on amplification of biopsies from patients with suspected localized cutaneous leishmaniasis. Lanes 1 to 14: DNA from patients biopsies; lane 15: L. (V.) braziliensis M2903 positive control; lane 16: no DNA; lane 17: size marker MWM ФX 174 Hae III

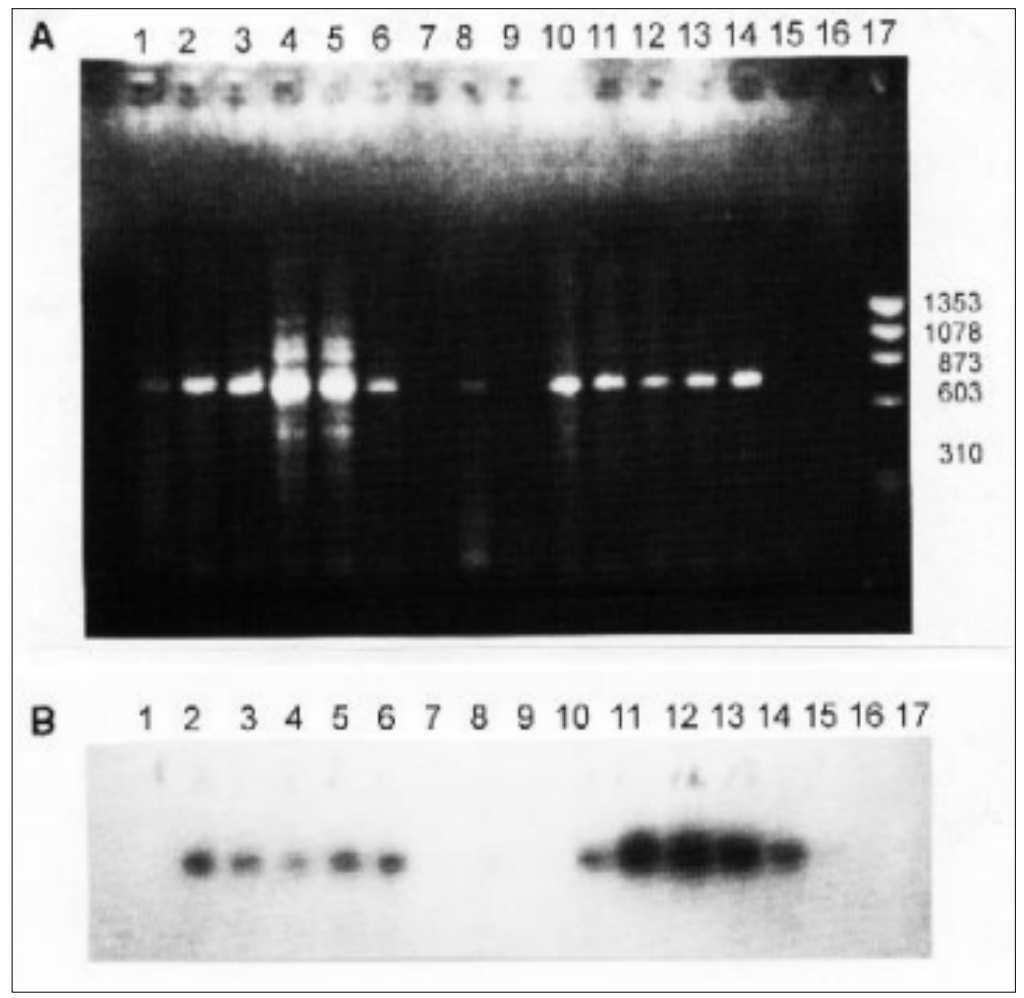

Fig. 2-A: specificity of polymerase chain reaction with 3J1 and 3J2 genomic species specific primers for Leishmania (Viannia) braziliensis. Photograph shows the products obtained on amplification of biopsies from patients with suspected localized cutaneous leishmaniasis. Lanes 1 to 14: DNA from patients biopsies; lane 15: $L($ L.) mexicana BEL 21 negative control; lane 16: no DNA; lane 17: size marker MWM $\Phi X 174$ Hae III; B: autoradiograph obtained on hybridizing the gel shown in Fig. 2A with Leishmania braziliensis complex specific probe LbJ38. Lanes 1 to 14: DNA from patients biopsies; lane 15: L. (L.) mexicana BEL 21 negative control; lane 16: no DNA; lane 17: size marker MWM ФX 174 Hae III 


\section{DISCUSSION}

Some years ago LCL was the most common clinical type of leishmaniasis in Mexico and all cases were considered to be caused by $L$. (L.) mexicana (Velasco et al. 1989a). In 1987, LCL was first recorded in Calera de Cofrados, a district near Tepic, the capital of the state of Nayarit. Since then, until 1994, 326 cases have been recorded (the Nayarit state health authority, unpublished data). It was thought that the etiological agent was $L$. $(L$.) mexicana, although the parasite species has not been identified (OPS/OMS-Secretaria de Salud 1994). Until 1994, Calera de Cofrados had an annual incidence of LCL of 3 cases per 1,000 inhabitants.

In this study, 14 patients from Calera de Cofrados district, with suspected LCL, had positive skin test with Montenegro's antigen. Confirmation of LCL and the identification of the Leishmania species were carried out by DNA analysis. PCR or southern blot were more accurate and less time consuming than the methods previously used in Mexico. The L. mexicana complex was discarded because none of the DNA samples taken from patient biopsies amplified with primers specific for this Leishmania complex (data not shown). However, all the biopsy DNA samples amplified with $\mathrm{B} 1$ and $\mathrm{B} 2$ primers specific for minicircle kDNA, from species belonging to the L. braziliensis complex (Fig. 1). Nuclear DNA from 12 out of 14 patients biopsies amplified with $3 \mathrm{~J} 1$ and $3 \mathrm{~J} 2$ primers, which are species specific for $L$. $(V$.) braziliensis, and they do not cross react with other species (Fig. 2A). These PCR products, except the products from biopsy 1 , gave positive hybridization with the LbJ38 probe, which is specific for the L. braziliensis complex (Fig. 2B). The results show that 14 patients were infected with members of L. braziliensis complex. Twelve out of 14 of the patients had LCL caused by L. (V.) braziliensis and three were probably infected with a variety of the same Leishmania species or possibly with a different member of the L. braziliensis complex. As far as we are aware, this is the first report of $L$. $(V$. braziliensis in Nayarit, Mexico. With these tools for DNA analysis we were able to demonstrate the presence of the L. braziliensis complex in Nayarit. In adition, we were able to distinguish between two variants of $L$. (V.) braziliensis and possibly between two different species. This was done with the interplay of wide specificity B1 and B2 primers, specific for the L. braziliensis complex (De Bruijn \& Barker 1992 ), and species specific primers 3J1 and $3 \mathrm{~J} 2$ for L. (Viannia) braziliensis and probe LbJ38, specific for L. braziliensis complex. According to Rodriguez et al. (1997), the second couple of primers amplify variants of $L$. $(V$.) braziliensis. In these studies, we have not been able to confirm that the patient biopsies, which did not amplify with these primers, had DNA from other Viannia species, or that sample biopsy 1, which amplified with these primers but did not hybridized with probe LbJ38 had DNA from $L$. (V.) guyanensis. Rodriguez et al. (1997), only tested Venezuelan isolates of L. braziliensis complex; therefore it is possible that these patients could have a Mexican variant of $L$. (V.) braziliensis that is not recognized by primers $3 \mathrm{~J} 1$ and $3 \mathrm{~J} 2$. These findings are interesting because Calera de Cofrados is a district with a very low rate of migration, and it is unlikely that this unidentified variant was introduced from another area.

In the endemic district of Nayarit, coffee plantations are located at $30 \mathrm{~min}$ from the village. The risk factor was identified as the harvesting and/or growth of coffee, regardless of patient age or sex. People from 5 to 65 years old had skin lesions due to LCL, although the most affected were between 5 to 14 years old; this is because mothers take their children to work at the plantations. There is an association between time spent on the coffee plantations and LCL, such that people who spend most of the time at the village did not get the Leishmania infection. Males were found to be the most affected since they spend more time on the coffee plantations than females. The suspected vectors are Lutzomyia cruciata, Lu. diabolica and Lu. shannoni, which were captured and identified at the plantation. In the village, Lu. oppidana and $L u$. texana were captured inside houses, but they are not anthropophilic. Wild rodents and some domestic animals are suspected to be animal reservoirs, but no studies have been done in this respect (OPS/OMS 1994). With this methodology and the tools used in this work, we are able to carry out studies on the identification of the principal vectors of each Leishmania species found in this Mexican state and the animal reservoirs implicated.

Because species from the L. braziliensis complex are more resistant to the glucantime treatment than species from the L. mexicana complex, these results are of great importance to the administration of appropriate treatment. This is specially true in light of the fact that glucantime is the anti-Leishmania drug currently used in Mexico. Patient 7 had multiple skin lesions and needed 60 doses of glucantime to cure and had a variant of $L$. (V.) braziliensis (the Nayarit state health authority, unpublished data).

\section{REFERENCES}

Ashford RW, Desjeux P, Deraadt P 1992. Estimation of populations at risk of infection with leishmaniasis. Parasitol Today 8: 104-105. 
Bray RS 1980. Leishmaniasis. In V Houba, Practical Methods in Clinical Immunological Series, The Immunological Investigations of Tropical Parasitic Diseases, Churchil Livingstone, London, p. 65-72.

De Bruijn MHL, Barker DC 1992. Diagnosis of New World leishmaniasis: specific detection of species of the Leishmania braziliensis complex by amplification of kinetoplast DNA. Acta Trop 52: 45-58.

Eresh S, Mc Callum SM, Barker DC 1994. Identification and diagnosis of Leishmania mexicana complex isolates by polymerase chain reaction. Parasitology 109: 423-433.

Hernandez-Montes O, Monroy-Ostria A, McCann S, Barker DC 1998. Identification of Mexican Leishmania species by analysis of PCR amplified DNA. Acta Trop 71: 139-153.

Lainson R 1983. The American leishmaniasis: some observations on their ecology and epidemiology. Trans $R$ Soc Trop Med Hyg 77: 569-596.

Lainson R, Shaw JJ 1987. Evolution, classification and geographical distribution. In W Peters, R KillickKendrick, The Leishmaniasis in Biology and Medicine, Academic Press, London, p. 1-120.
OPS/OMS, Secretaria de Salud 1994. Informe técnico de la I Conferencia Interamericana para el control de la leishmaniasis, Mexico.

Perez-Motul J, Bala-Tzeek L, Canto-Lara S 1994. Identificación de protozoarios del genero Leishmania con sondas biotinadas de kDNA en la Peninsula de Yucatan, Mexico. Rev Biom 5: 60-69.

Rodriguez N, De Lima H, Rodriguez A, Brewster S, Barker DC 1997. Genomic DNA repeat from Leishmania (Viannia) braziliensis (Venezuelan strain) containing simple repeats and microsatellites. Parasitology 115: 349-358.

Sambrook J, Fritsch EF, Maniatis T 1989. Molecular Cloning, A Laboratory Manual, 2nd ed., Cold Spring Harbor Laboratory Press, New York, p. 9.38-9.40.

Velasco-Castrejon O, Savarino S, Neva F, GuzmanBracho C 1989a. Los agentes etiológicos de las leishmaniasis cutáneas en México. Presencia de $L$. braziliensis en Mexico. Rev Lat Amer Microbiol 31 : 231-234.

Velasco-Castrejon O, Savarino SJ, Walton BC, Gam AA, Neva F 1989b. Diffuse cutaneous leishmaniasis in Mexico. Am J Trop Med Hyg 4: 280-288. 
L. braziliensis in Mexico - Gustavo Sanches-Tejeda et al. 